www.jmscr.igmpublication.org

Impact Factor (SJIF): 6.379

Index Copernicus Value: 71.58

ISSN (e)-2347-176x ISSN (p) 2455-0450

crossref DOI: https://dx.doi.org/10.18535/jmscr/v6i5.10

Journal Of Medical Science And Clinical Research

\title{
Hypothyroidism and Hypogonadism Associated with Slipped Capital Femoral Epiphysis: A Case Report
}

\author{
Authors \\ Dr Viral Kumar ${ }^{1}$, Dr Lakshmi Priya ${ }^{2}$ \\ ${ }^{1}$ Associate Professor, Deptt of General Medicine, PGIMS Rohtak \\ Email: drviralsangwan@yahoo.com, Mobile 9896130304 \\ Address House No 1/9 J, Medical Campus, Rohtak, Haryana, India \\ ${ }^{2}$ Resident, Deptt of General Medicine, PGIMS Rohtak, Haryana, India \\ Email priya.lakshmi.1791@gmail.com
}

\begin{abstract}
Primary hypothyroidism is one of the most common endocrine diseases. It is associated with hypogonadotropic hypogonadism, which is reversible with thyroid hormone replacement therapy. Slipped Capital Femoral Epiphysis most commonly affects the adolescent population, usually individuals between 8 and 15 years old. However, there are few case reports of older patients in the literature to date. Here, we present the case of a 34-year-old male patient, who presented with absence of secondary sexual characteristics and unilateral limp. Upon clinical, biochemical and radiological investigations, the patient was found to have primary hypothyroidism and secondary hypogonadism associated with skeletal immaturity and Slipped Capital Femoral Epiphysis (SCFE).

Keywords: Slipped Capital femoral epiphysis, Hypothyroidism, Hypogonadism.
\end{abstract}

\section{Introduction}

Primary hypothyroidism is one of the most common endocrine diseases.An epidemiological study in the Indian population suggested the overall prevalence of hypothyroidism to be $10.95 \% .^{1}$ Primary hypothyroidism is associated with hypogonadotropic hypogonadism, which is reversible with thyroid hormone replacement therapy. Slipped Capital Femoral Epiphysis (SCFE) most commonly affects the adolescent population between 8 and 15 years, however, there are few case reports of older patients in the literature todate. ${ }^{2,3}$ It is believed that the aetiology is multifactorial and may include obesity, trauma and, less frequently, endocrine pathologies comprising hypothyroidism, hypogonadism and panhypopituitarism. ${ }^{4}$ Thyroid hormone deficiency can play a significant rolein reducing the stability of the growth plate and then contributeto the pathogenesis of the proximal femoral glide in SCFE.

\section{Case Presentation}

A 34-year-old male, born with nonconsanguineous marriage presented with complaints of absence of secondary sexual characteristics and unilateral painful limp of the left lower limb following trivial trauma. Patient denied any history of vision abnormalities, headache, seizures, loss of smell, loss of hearing, 
testicular pain or trauma. There was no history of heat or cold intolerance, constipation, diarrhoea, colicky pain abdomen or hematuria. All his siblings had no such complaints and had normal height. The physical examination at presentation revealed a short stature, $152.5 \mathrm{~cm}$, with a raised Body Mass Index of $25.97 \mathrm{~kg} / \mathrm{m}^{2}$ (overweight). Patient had coarse facial features, hoarseness of voice, dry skin and dull facial expression. There was absence of facial, axillary, and pubic hair with reduced bilateral testicular volume $(6 \mathrm{ml})$ and decreased stretched penile length $(8 \mathrm{~cm})$. There was limited range of mobility of left hip joint. Biochemical parameters revealed raised TSH (77.98IU/L), reduced T3 $(25.65 \mathrm{ng} / \mathrm{dl})$ and T4(0.420 microg/dl). Serum FSH and LH were decreased at $0.418 \mathrm{mIU} / \mathrm{ml}$ and $0.214 \mathrm{mIU} / \mathrm{ml}$ respectively. They remained decreased even after GnRH stimulation. Serum Testosterone was reduced at $2.50 \mathrm{ng} / \mathrm{dl}$ and Vitamin $\mathrm{D}$ was also decreased at $6.26 \mathrm{ng} / \mathrm{ml}$. Ultrasound of the neck revealed bilateral lobes of thyroid altered in echotexture and mildly increased in echogenicity suggestive of thyroiditis. Radiography of pelvis revealed SCFE on the left side.

Table 1 Hormonal profile at presentation

\begin{tabular}{|l|c|}
\hline TSH & $77.98 \mathrm{mIU} / \mathrm{L}(0.4-4.10)$ \\
\hline T3 & $25.65 \mathrm{ng} / \mathrm{dl}(67-180)$ \\
\hline T4 & $0.420 \mathrm{microg} / \mathrm{dl}(4.8-11.4)$ \\
\hline S. FSH & $0.418 \mathrm{mIU} / \mathrm{ml}(2.60-11.0)$ \\
\hline S. LH Fost GnRH & $0.214 \mathrm{mIU} / \mathrm{ml}(1.5-9.3)$ \\
\hline $\begin{array}{l}\text { S. FSH } \\
\text { stimulation (2 hrs) }\end{array}$ & $0.37 \mathrm{mIU} / \mathrm{ml}(1.27-19.26)$ \\
\hline $\begin{array}{l}\text { S. LH Post GnRH stimulation } \\
\text { (2 hrs) }\end{array}$ & $0.02 \mathrm{mIU} / \mathrm{ml} \mathrm{(1.24-8.62)}$ \\
\hline $\begin{array}{l}\text { S. LH Post GnRH stimulation } \\
\text { (4 hrs) }\end{array}$ & $0.10 \mathrm{mIU} / \mathrm{ml} \mathrm{(1.24-8.62)}$ \\
\hline S. Prolactin & $5.52 \mathrm{ng} / \mathrm{ml} \mathrm{(2.64-13.13)}$ \\
\hline S. Testosterone & $2.50 \mathrm{ng} / \mathrm{dl}(350-1000)$ \\
\hline S. Vitamin D & $6.26 \mathrm{ng} / \mathrm{ml} \mathrm{(50-70)}$ \\
\hline
\end{tabular}

Fig 1 X-ray pelvis with bilateral hip joint - showing Trethowan sign seen in SCFE. (The line of Klein describes a line along the superior edge of the neck of the femur. The line should normally intersect the lateral part of the superior femoral epiphysis. If the line of Klein fails to intersect the epiphysis during the acute phase, it is called Trethowan sign seen in SCFE)

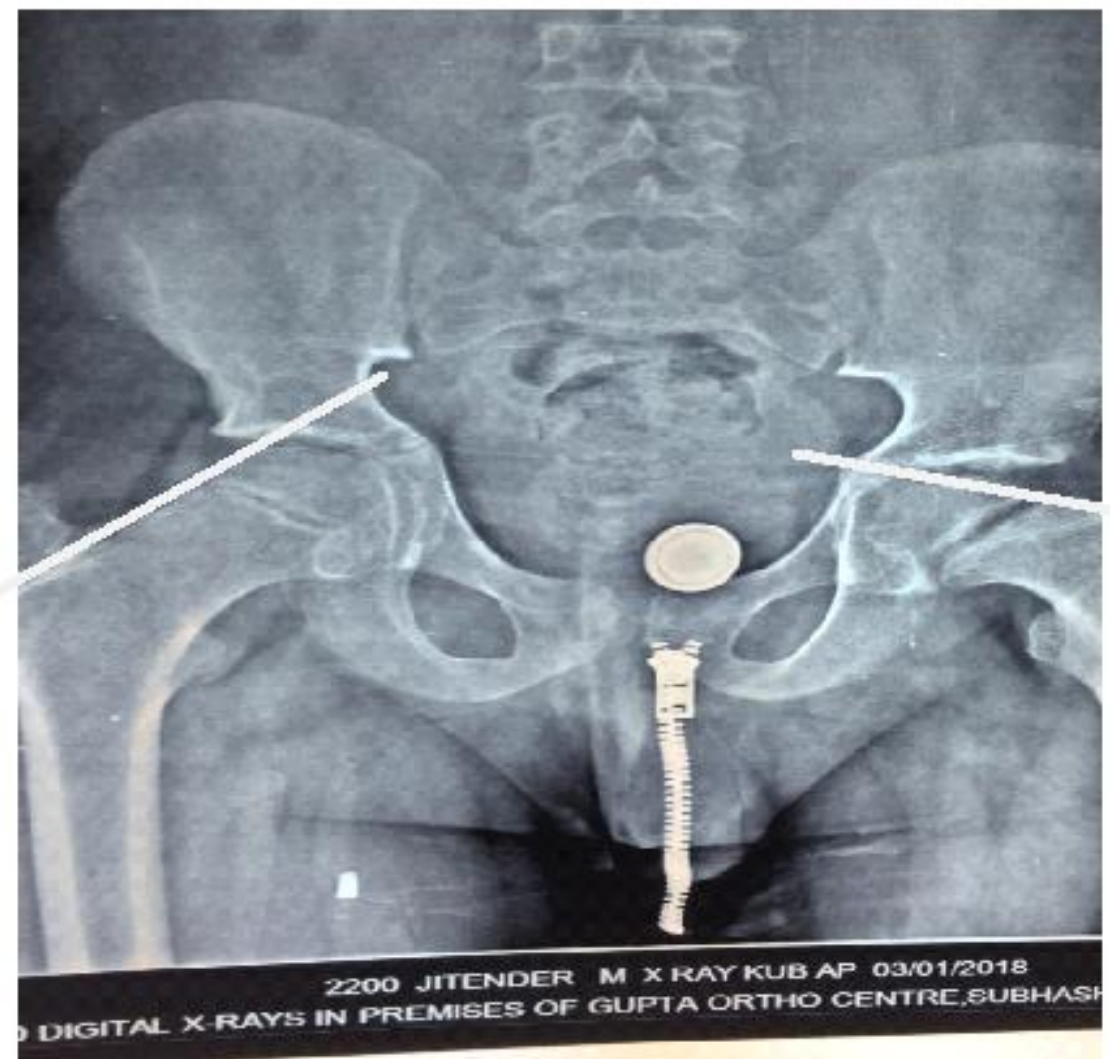


Fig 2 MRI pelvis showing SCFE

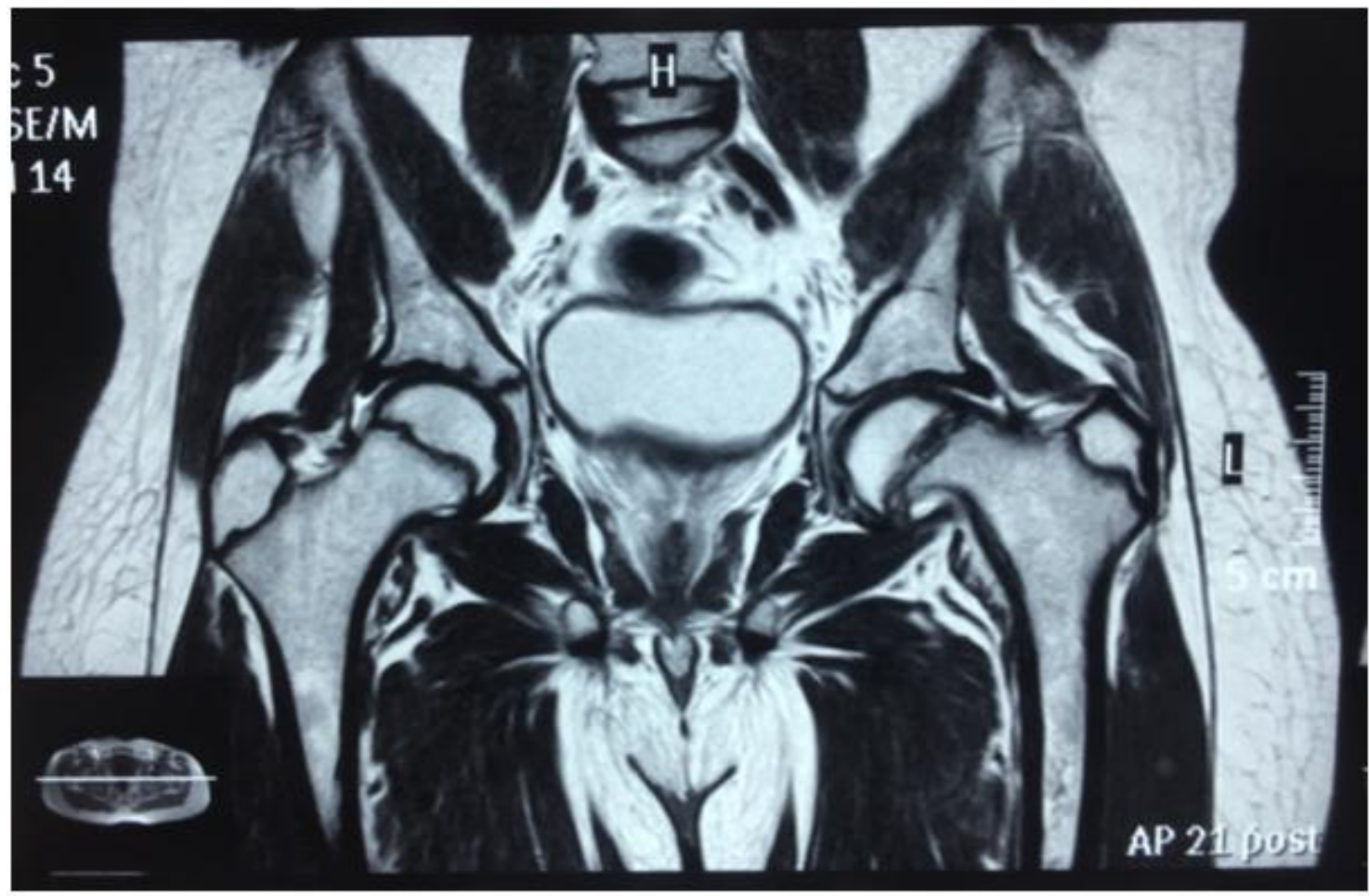

\section{Discussion}

SCFE is the most common hip disorder affecting the adolescent population. SCFE is known to affect boys more often than girls. ${ }^{5}$ The aetiology of SCFE is still unclear, and the role of endocrine disruption remains controversial. Thyroid and growth hormones are the most commonly affected hormones. Both are necessary for growth and maturation of the cartilage, with subsequent calcification and replacement by mineralized osteoid. Primary hypothyroidism has been reported to alter the secretion of several pituitary hormones including GH, gonadotropins, and ACTH. Thyroid hormone also has profound influences on serum Sex hormone binding globulin (SHBG) concentrations. It results in a decrease in SHBG and total testosterone and reduces the level of free testosterone. Within 6 weeks of correction of hypothyroidism with replacement thyroid hormone, free testosterone concentrations return to normal in hypothyroid men with subnormal serum free testosterone concentrations. There are very few case reports in the worldwide literature of adult patients who presented with SCFE. It should be emphasized that all the published cases were associated with different endocrine disorders, either pituitary diseases or, more rarely, hypothyroidism, and all were of primary origin. Therefore, it is important to do a hormonal profile in these patients to find out a possible aetiology.

\section{Acknowledgements}

We are highly thankful to residents and staff of my ward for constant support and encouragement for publication of all interesting cases.

\section{References}

1. Unnikrishnan AG, Kalra S, John M, Sahay RK, Ganapathi B, authors. Prevalence of hypothyroidism in India. Disorders of Thyroid Function. Thyroid. 2012;22(Suppl 1):91.

2. Loder RT: Slipped capital femoral epiphysis. Am Fam Physician 1998,57:2135-2142. 2148-2150. A published erratum appears in Am FamPhysician 1998, 58:52.

3. Gholve PA, Cameron DB, Millis MB: Slipped capital femoral epiphysisupdate. CurrOpinPediatr 2009, 21:39-45. 
4. Heyerman W, Weiner D: Slipped epiphysis associated withhypothyroidism. J PediatrOrthop 1984, 4:569-573.

5. Loder, Randall T, Starnes, Trevor, Dikos, Greg. Atypical and typical (Idiopathic) Slipped Capital Femoral Epiphysis: Reconfirmation of the Age-Weight Test and Description of the Height and AgeHeight Tests. JBJS, 2006: 88; 1574-81. 